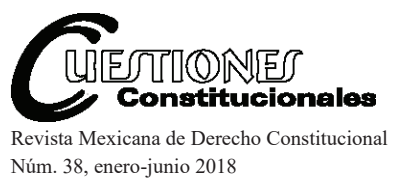

Núm. 38, enero-junio 2018

\title{
EL CONSTITUYENTE PAULINO MACHORRO Y EL CENTENARIO DE LA CONSTITUCIÓN DE QUERÉTARO*
}

\author{
J. Jesús Orozco HenríQueZ** \\ Sumario: I. Introducción. II. Machorro como funcionario \\ público. III. Machorro como ministro de la Suprema Corte. \\ IV. Machorro como barrista.
}

\section{INTRODUCCIÓN}

Constituye un alto honor participar en este magno evento de celebración de los Cien Años de nuestra Constitución, organizado conjuntamente por la Suprema Corte de Justicia de la Nación y la Barra Mexicana, Colegio de Abogados, en este majestuoso recinto de la justicia. Vaya mi sincero agradecimiento al señor ministro presidente de este alto tribunal, don Luis María Aguilar Morales, así como al destacado abogado don Ricardo Ríos Ferrer, presidente de la Barra, por el privilegio.

Celebro la conformación de una Comisión Organizadora del Poder Judicial de la Federación para los festejos del Centenario - como parte del acuerdo entre los tres poderes para tal efecto, y que se haya encomendado

* Intervención en la ceremonia "La evolución de la SCJN y su relación con la Barra Mexicana, Colegio de Abogados. Una reflexión a 100 años de la Constitución”, celebrada en la Suprema Corte de Justicia de la Nación el 2 de febrero de 2017.

** Investigador titular en el Instituto de Investigaciones Jurídicas y miembro de la Junta de Gobierno de la UNAM, así como comisionado ex presidente de la Comisión Interamericana de Derechos Humanos y miembro de la Barra Mexicana, Colegio de Abogados, A. C. 
la ardua tarea de su coordinación al connotado jurista ministro don José Ramón Cossío- , con lo cual se dejará un gran legado por escrito, que dará testimonio de la participación de diversos sectores de la población y las distintas ramas de gobierno para conmemorar estos cien años que, además de tener un carácter festivo, nos hacen conscientes de los logros alcanzados y los grandes retos hacia el futuro.

En ese contexto, me parece oportuna la coorganización de este evento por parte de dos instituciones que, a lo largo de su existencia, han contribuido de manera significativa al fortalecimiento del Estado de derecho en México. Por un lado, el Poder Judicial de la Federación, con su larga tradición como principal garante de los derechos fundamentales y, por la otra, el Colegio de Abogados con mayor prestigio del país, que se ha distinguido no sólo por su acompañamiento constructivo y crítico del gobierno para el fortalecimiento de la cultura de la legalidad, sino porque también ha sido prolijo en las actividades académicas que abonan para la formación y desarrollo de sus agremiados.

En la magna efeméride que nos convoca, se me ha solicitado que me refiera a la vida y obra de don Paulino Machorro Narváez, ilustre jurista que tuvo el privilegio único de reunir, en sucesivos momentos, la triple calidad de haber sido diputado al Congreso Constituyente de 1916-1917; ministro de la Suprema Corte de Justicia de la Nación, de 1928 a 1934, y presidente de la Barra Mexicana, Colegio de Abogados, en 1940; de ahí la plena justificación de homenajear en esta ocasión a don Paulino, quien también fue profesor, entre otras instituciones, de la entonces Escuela Nacional de Jurisprudencia de la Universidad Nacional Autónoma de México.

Cabe destacar que, en el marco de los compromisos asumidos por el Poder Judicial de la Federación para la Conmemoración del Centenario de la Constitución, el ministro presidente don Luis María Aguilar se dio a la tarea de propiciar el conocimiento, difusión y reflexión sobre nuestra norma fundamental, así como su historia y aplicación por el propio Poder Judicial, poniendo a disposición de todas las personas interesadas un conjunto de publicaciones entre obras conmemorativas, compilaciones y estudios monográficos y facsimilares que, sin duda, resultan de gran interés y provecho no sólo para especialistas sino también para el público en general, dentro de las cuales se cuenta el libro Apuntes para el estudio del derecho constitucional mexicano, de Paulino Machorro Narváez, editado por el Poder Judicial de la Federación en noviembre de 2015. 
En la introducción de la mencionada obra, el ministro Cossío apunta que la Suprema Corte de Justicia de la Nación, como una de las instituciones que ha participado activamente en el tránsito histórico, desde hace más 190 años, y en tanto intérprete y garante de la Constitución, ha sido factor sustantivo en la definición de los principios que conforman a un Estado constitucional y democrático de derecho. En tal virtud, a fin de contribuir a formar a las personas en el contenido de nuestra Constitución y sus significados, así como a construir un debate abierto y franco en torno a nuestro pasado y los retos que plantean los tiempos actuales, se ha propuesto llevar a cabo diversas actividades encaminadas a socializar la Constitución.

Dentro de los temas que se abordan en estas actividades, se encuentra, entre otros, el proceso de gestación, consolidación y aplicación de la Constitución de 1917, respecto de lo cual el ministro y también acusioso investigador José Ramón Cossío llevó a cabo un gran hallazgo en la obra de don Paulino Machorro Narváez.

En el estudio introductorio de la mencionada obra, el ministro Cossío nos relata:

Con motivo del estudio que estaba preparando respecto a los trabajos que don Felipe Tena Ramírez escribió en derecho constitucional y juicio de amparo, me di a la tarea de leer los escritos que de ambas materias se publicaron en nuestro país en la primera parte del siglo XX. Siguiendo el lugar común, supuse que más allá de algunas exposiciones parciales, la primera obra integral respecto de la Constitución de 1917 fue la producida por Miguel Lanz Duret en 1931, y que desde ahí hasta la publicación en 1944 de la primera edición del derecho constitucional mexicano del propio Tena, no se había publicado ningún otro texto sistemático en la materia. Sin embargo, al repasar con más cuidado la producción de aquellos años, me encontré que a partir de septiembre de 1932 don Paulino Machorro Narváez entregó un total de diecinueve colaboraciones mensuales prácticamente consecutivas a la revista La Justicia, las que como conjunto denominó "Apuntes para el estudio del derecho constitucional mexicano". A mi parecer - aduce el ministro Cossío - los trabajos de Machorro, o si se quiere su unidad, pretenden tener el estatuto de obra sistemática y completa de derecho constitucional, y por lo mismo debe ser incorporada con ese carácter a la bibliografía nacional. Este es el propósito de la edición que hoy analiza la Suprema Corte y que me ha correspondido presentar. 
Del propio estudio introductorio de la mencionada obra, tomaré algunos datos biográficos de don Paulino Machorro, para después referirme a su vida y obra, destacando, sobre todo, su etapa primera intermitente en cuanto funcionario público y abogado en ejercicio libre; posteriormente, como ministro de la Corte y, finalmente, presidente de la Barra Mexicana, Colegio de Abogados.

El lugar de nacimiento de Machorro es motivo de confusiones, pues, por haber hecho la mayor parte de sus estudios en Jalisco, hay quienes lo suponen oriundo de ese estado, a cuyo 18o. distrito electoral representó en el Congreso Constituyente de 1916-1917. En realidad, nació en la ciudad de Durango en septiembre de 1887, aunque pronto se trasladó a Guadalajara para estudiar en el seminario conciliar, la escuela de varones y la escuela de jurisprudencia; de esta última se graduó en mayo de 1901. Destaco que esos años coinciden con el proceso, generado durante el Porfiriato, en el que el presidente Díaz llevó a cabo las maniobras y reformas jurídicas suficientes para permitir su propia reelección $\mathrm{y}$, consecuentemente, un régimen de represión y merma de las libertades. Posteriormente, Machorro se desempeñó como agente del Ministerio Público en Teocaltiche, Jalisco, y como juez de la ciudad de Aguascalientes. Ahí fundó la llamada revista Del Centro, en compañía de abogados, historiadores y artistas. En 1906, comenzó a ejercer la profesión de abogado en Guadalajara, y en 1911 se afilió al Partido Liberal Jalisciense, ganando las elecciones municipales de la misma ciudad. En 1913, en medio de la efervescencia vivida por nuestro país con motivo de la "Decena Trágica", participó en mítines populares en torno a la denominada Liga de Amigos del Pueblo, la cual participó en 1914 en la formación del gobierno del general Manuel M. Diéguez y fue designado director de la escuela preparatoria de Jalisco. En 1915 y con motivo de la evacuación del gobierno constitucionalista de Guadalajara, comenzó a escribir artículos en favor de la causa revolucionaria en el periódico Vanguardia, de Orizaba.

También en 1915, acompañó a De la Huerta a la Ciudad de México, recién recuperada por el gobierno constitucionalista, y poco después fue designado Procurador de Justicia del Distrito y Territorios Federales, cargo del que se separó al iniciar los trabajos del constituyente a finales de 1916. Además de presidir la segunda comisión constitucional, Machorro participó en tribuna en 18 ocasiones al discutirse diversos artículos de lo que eventual sería el texto constitucional. Sus intervenciones fueron técnicas, políticas y sociales. 
Terminado el proceso constituyente, en julio de 1917 fue nombrado oficial mayor de la Secretaría de Gobernación. Inmediatamente después participó como diputado del Congreso de la Unión en la XVIII Legislatura (19171918) y, por licencia de la Cámara, volvió a esa Secretaría hasta la muerte de Carranza. En 1924 fue nombrado presidente del jurado de infracciones fiscales de la Secretaría de Hacienda.

En diciembre de 1928, el Senado de la República aprobó la propuesta del presidente Portes Gil para que Machorro ocupase el cargo de ministro de la Suprema Corte de Justicia de la Nación. En él se desempeñó hasta finales de 1934, cuando, con motivo de la Reforma promovida por el presidente Cárdenas, fueron removidos prácticamente la totalidad de los integrantes del máximo tribunal de la República. Con posterioridad, se dedicó al ejercicio profesional de la abogacía, habiendo sido electo en 1940 presidente de la Barra de Abogados. Después de algunos años de vida independiente y académica, murió en la Ciudad de México en marzo de 1957.

Permítaseme profundizar en algunos de los aspectos más destacados de la fructífera vida profesional de don Paulino Machorro Narváez, primero como funcionario público, después como ministro y, finalmente, como abogado postulante y presidente de la Barra Mexicana, Colegio de Abogados.

\section{MACHORRO COMO FUNCIONARIO PÚBLICO}

Con los pocos datos biográficos que tenemos de don Paulino, podemos aventurar que, a la par de ser funcionario público, comulgaba con ideas revolucionarias que cuestionaban las estructuras anquilosadas o desgastadas que venían del Porfiriato. Es decir, no dejó de tener una visión crítica, a pesar de formar parte del aparato gubernamental. Es de destacarse que, siendo juez en la ciudad de Aguascalientes, fundó la revista Del Centro en compañía de abogados, historiadores y artistas, lo cual deja ver en él una visión universal y no la acotada de un juez regional, que bien pudo haber enfrentado imposiciones o cacicazgos que eran propios de la época. Sin duda, este detalle muestra el carácter independiente de su pensamiento.

Su afiliación, como se mencionó, al Partido Liberal Jalisciense en 1911 y su triunfo en las elecciones municipales de la misma ciudad, nos deja ver a un hombre tenaz y ansioso por lograr cambios fundamentales desde sus posiciones políticas. 
Identificó problemáticas relevantes de la época, refiriéndose a ellas de manera clara: el férreo individualismo prevaleciente, la dominación oligárquica, la concentración terrateniente y la pobreza generalizada. Asimismo, señaló los problemas generalizados por las nuevas riquezas del subsuelo y la debilidad del gobierno en esos temas, así como el falseamiento de todo el sistema para permitir a Porfirio Díaz el ejercicio político. Todo ello da muestra del valor que tuvo en tribuna, pues por sus venas corría la firme convicción de que el régimen constitucional significa la sujeción de los funcionarios de más alta categoría a un sistema legal que fija su competencia, lo que bien podría traducirse hoy en lo que conocemos como el principio básico de que nadie puede estar por encima de la ley y, más aún, nadie puede estar por encima de la Constitución.

En la expresión de sus ideas se nota claramente el fácil uso de categorías generales de ordenación, apelando incluso a algunas de ellas no estrictamente jurídicas, con lo cual, desde mi perspectiva, es una característica fundamental para cualquier operador jurídico que pretenda lograr niveles mínimos de evolución interpretativa. Incluso, para Machorro la Constitución de 1917 fue producto de la evolución histórica y constitucional de México y no tanto un producto directo de la cruda lucha revolucionaria. En este sentido se ve también, en su pensamiento, un carácter eminentemente pacifista. No en balde el ministro Cossío refiere, en la obra sobre su vida, que: "no pasó revista Machorro al proceso revolucionario mismo".

Bajo ese tenor, podemos presumir que don Paulino se condujo como un liberal estructurado en su vida como funcionario público, a pesar de haber detentando posiciones que de suyo generan la acumulación de un gran poder como lo es ser agente del Ministerio Público, procurador de justicia, oficial mayor de la Secretaría de Gobernación, o incluso presidente del Jurado de Infracciones Fiscales de la Secretaría de Hacienda, entre otros cargos públicos que desempeñó.

Es importante mencionar que en esa etapa de su vida, de 1925 a 1928 impartió la catedra de Derecho constitucional en la Escuela Nacional de Jurisprudencia, por lo que a todas las características anteriormente anotadas de su vida profesional se agrega el de ser, en ese lapso y también con posterioridad a 1940, un destacado académico.

Con este carácter y justamente también por haber formado parte del constituyente queretano, se sentía obligado - con toda razón — a inculcar a los mexicanos de varias generaciones que la Constitución de 1917 es una de 
las más grandes obras políticas que jamás se hayan hecho en nuestro país. Por ello, invitaba a estudiarla, analizarla, cuidarla y respetarla.

\section{Machorro como ministro de la Suprema Corte}

Durante la etapa de don Paulino como ministro, se pueden leer criterios y votos de relevancia para el orden jurídico. De los que pueden consultarse en los sistemas electrónicos de la Suprema Corte, nos deja verlo como una persona preocupada por el respeto de los derechos humanos y por la conservación de un mínimo de Estado de derecho.

Es importante mencionar que, de muchos de sus criterios, se advierte un incipiente pero claro control difuso de la Constitución, tanto de leyes federales como locales, así como una reiterada interpretación directa de preceptos constitucionales.

Por su claridad, conviene citar a la letra, la opinión expuesta por el ministro Machorro en la sesión del 21 de noviembre de 1930, y cito:

...entonces hay que ver, no nada más la ley local, sino la ley contrastada con la Constitución, conforme al artículo 133 de la propia Ley Suprema que establece que esta propia Constitución es la Ley Suprema y que todas las leyes, por lo mismo, deberán sujetarse a aquélla.

...y si según esa ley aparece que un delito cometido por medio de la prensa, por llamársele delito contra la reputación y no contra el orden público evade el cumplimiento de una garantía constitucional, entonces hay que decir que esa ley es anticonstitucional, que no debe aplicarse esa ley, sino que debe aplicarse el precepto constitucional...

También es ilustrativa la siguiente tesis:

El principio de división de poderes exige que no puedan confundirse las facultades del juez y del Ministerio Público; en tal virtud, solamente las diligencias practicadas por el juez del proceso, tienen el valor pleno que concede la Constitución para fundar las resoluciones a que se refieren los diversos artículos de la misma ley fundamental; no obsta a lo dicho, lo que dispone el artículo 102 del Código Federal de Procedimientos Penales, que por ser anterior a la Constitución de 1917, no tiene aplicación contra lo estatuido en ella. 
De la mano de los anteriores criterios, don Paulino impulsó tesis de las que podemos notar su preocupación por la protección efectiva de los derechos humanos, esto es, las otrora garantías individuales. En dichos criterios podemos ver que, con respecto a la materia penal, trató siempre de garantizar el debido proceso y que, al determinarse la pena, se cumplieran con los principios aplicables a fin de evitar arbitrariedades de las autoridades, todo lo cual lo sostenía a la luz de los preceptos constitucionales.

Mostró un ágil manejo de ciertas categorías jurídicas como el orden constitucional, el coto vedado a la autoridad, el arbitrio judicial, las presunciones legales, la procedencia del amparo, entre otras que le sirvieron para guiar su pensamiento protector.

En su paso por la Corte, dejó una gran aportación en la elaboración del dictamen que sirvió al Pleno de la Corte para emitir, el 3 de septiembre de 1934 a solicitud del procurador general de la República, un acuerdo para la determinación de la jurisdicción que impera en las Islas Marías. En ese estudio constitucional, mencionó, con su estilo claro y estructurado, que por lo que toca a la ley que rige en las Islas Marías, por ningún motivo puede sostenerse que no aplique ley alguna, pues esto sería sostener que una parte del territorio nacional se encuentre bajo un estado de barbarie, que significa la ausencia absoluta de una ley que rija la conducta de los hombres. Con gran capacidad interpretativa, concluyó que en dichas Islas debía aplicarse el Código Penal del Distrito Federal y dejó a la determinación de los tribunales si tenía que ser el de 1871, el de 1929 o el de 1931, desterrando la posibilidad de que bajo la vigencia de la Constitución, se pudiera pensar en un ámbito espacial del territorio en el que privara el estado de naturaleza.

Utilizó como una de sus referencias el pensamiento de Ignacio Mariscal, constituyente de 1857 y posteriormente ministro de Justicia, quien emitió una circular en la que claramente expresó que: "todo podría concluirse de la interpretación constitucional, menos que por falta de legislación secundaria, no haya funcionarios a quienes ocurrir para hacer efectivas las primeras garantías sociales, los principales fines de la Constitución misma".

Las tesis, además de ser un gran aporte en materia jurídica, son redactadas de forma clara y precisa, con lo cual nos deja ver la facilidad del ministro Machorro para exponer sus argumentos y abordar la cuestión planteada desde la Constitución, mostrando un pensamiento avanzado a su época.

En esas sesiones en que la mayoría de los debates en que se enfrascaban los ministros de la Corte eran de mera legalidad, don Paulino sorprendía con 
la interpretación que realizaba desde la Constitución. De ahí su relevancia como ministro, en el entendido de que fue contemporáneo de figuras como Salvador Urbina, a la sazón presidente del más alto tribunal.

También es importante resaltar otra opinión del ministro Machorro en la que sostenía la teoría de que no debía existir el sobreseimiento, sino que se debía amparar o negar el amparo. Dentro de las ideas que sustentaban esa teoría, expuso algo muy valioso que debería de ser ponderado por los órganos jurisdiccionales en nuestros días, consistente en que se debía privilegiar la admisión de los juicios a través de los cuales se protegieran los derechos de las personas, ya que resultaba absurdo que se desecharan las demandas sin conocer la totalidad de los elementos que eventualmente puede generar el juicio.

Con lo anterior, nos podemos formar una idea respecto de la personalidad de don Paulino en su faceta de ministro de la Corte: un juez garantista que busca salvaguardar el Estado constitucional de derecho a través de desentrañar los preceptos constitucionales, así como proteger los derechos fundamentales de forma amplia y efectiva, a través de la interpretación que más beneficie a la persona, y siempre privilegiando el derecho de los justiciables para acceder a la justicia.

\section{MACHORRO COMO BARRISTA}

De su labor al frente de la Barra, en realidad se tienen pocos datos, por lo que invito a nuestros colegas barristas aquí presentes a impulsar alguna investigación al interior del Colegio para rescatar el material, que seguramente será valioso, sobre los actos relevantes de don Paulino como su presidente.

Menciono dos datos interesantes:

Dejó de ser ministro de la Corte en el año en que a los ministros se les solicitó afiliarse al Partido Nacional Revolucionario. Durante los seis años de la presidencia cardenista, la Corte sufrió diversos ataques.

Su elección como presidente del Colegio coincide con la conclusión del gobierno del general Cárdenas, periodo en el cual no fue seleccionado para continuar en el cargo de ministro, a pesar de que había una propuesta en ese sentido emitida por don Toribio Esquivel Obregón en nombre de la Academia Mexicana de Legislación y Jurisprudencia. 
Debo compartir con ustedes que al haberme adentrado en la vida y obra de don Paulino Machorro Narváez, advertí que, además de su perfil como político, constituyente, abogado y ministro, tuvo una importante faceta como académico y profesor universitario de Derecho constitucional y Derecho penal. Esto me produjo recurrentes pensamientos relacionados con el garantismo que, como mencioné en algún trabajo, es un programa que si bien surgió en el ámbito del derecho penal cabe extenderlo, como bien observa Ferrajoli, a otras ramas del ordenamiento, como el derecho constitucional, el derecho internacional y el derecho procesal, entre otros. Al respecto, es posible forjar, en relación con los derechos fundamentales y otras técnicas de garantías o criterios de legitimación, modelos garantistas no sólo en el ámbito del conocimiento jurídico para identificar lagunas o antinomias, o bien proponer soluciones como parte de la función crítica y proyectiva asignada a la ciencia jurídica y con motivo del litigio constitucional, sino igualmente en el ejercicio de la función jurisdiccional, en cuanto a la tarea de los juzgadores de impartir justicia en el Estado constitucional democrático de derecho y garantizar la protección efectiva de los derechos humanos, por lo que es posible afirmar que don Paulino Machorro Narváez, si bien en sus ensayos constitucionales gustaba de citar a Jellineck, Kelsen o Duguit, atendiendo también a su ejercicio jurisdiccional, puede estar catalogado dentro de los juristas del siglo XX que buscaron acercarse a lo que hoy conocemos como el paradigma garantista del constitucionalismo democrático. 